\title{
Síndrome diarreico y carcinoma de células renales
}

\author{
A. Benítez Roldán, C. González López, F. Torres Olivera ${ }^{1}$ A. Vallejo Benítez ${ }^{1}$, F. Pellicer Bautista \\ y J. M. Herrerías Gutiérrez
}

Servicios de Aparato Digestivo y ${ }^{I}$ Anatomía Patológica. Hospital Universitario Virgen Macarena. Sevilla

\section{CASO CLÍNICO}

Varón de 36 años que consultó por cuadro de diarrea crónica y pérdida de peso.

Se le realiza estudio analítico, que consistió en bioquímica general, hemograma, TSH, estudio inmunológico, perfil celiaco y parásitos de heces que fue normal. La proteína $\mathrm{C}$ reactiva estaba elevada. Se le realizó colonoscopia hasta ciego que fue normal y en el tránsito intestinal baritado no se identificó ninguna alteración.

En la ecografía abdominal se evidenció una masa renal izquierda en polo superior de más de $4 \mathrm{~cm}$ de diámetro, redondeada, isoecoica con áreas hipoecoicas en su interior que podrían ser compatibles con áreas necróticas (Fig. 1).

La realización de la TAC confirmó la existencia de esa lesión de 4,3 cm, hipodensa, limitada al riñón, sin afectar a la grasa perirrenal ni al pedículo vascular. El paciente se remitió al servicio de Urología y se le sometió a nefrectomía laparoscópica izquierda, visualizándose macroscópicamente una lobulación en uno de sus polos, con cápsula de Gerota íntegra y sin otras alteraciones macroscópicas significativas. En los cortes se identificó en dicho polo, una lesión redondeada, bien delimitada, de 4,8 x 4,5 cm, con parénquima amarrillo, parduzco, con pequeñas cavidades milimétricas y friable al corte, quedando muy próximo a la cápsula renal. Se diagnosticó de carcinoma de células renales papilar tipo 2 de Delahunt y Eble (Fig. 2). Actualmente el paciente se encuentra asintomático, remitiendo tras la intervención, del cuadro diarreico por el que consultó.

\section{COMENTARIOS}

El carcinoma de células renales papilar es un tumor maligno, derivado del epitelio del túbulo renal con una prevalencia de un 10-15\% con predominio en varones. Generalmente está bien delimitado, es globular de color marrón. Suele tener una localización excéntrica en la corteza. Existen dos tipos de carcinoma de células renales de tipo papilar que Delahunt y Eble designaron tipo 1 y tipo 2 (1). El tipo 2 muestra células más grandes, con citoplasma abundante, eosinófilo. Los núcleos se disponen en patrón pseudoestratificado y son grandes, esféricos con nucleolo prominente.

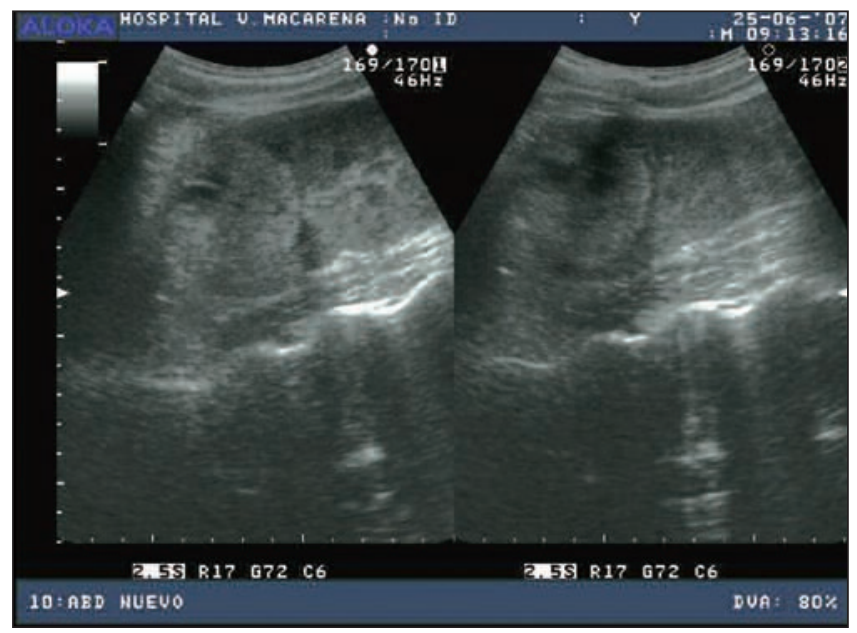

Fig. 1.

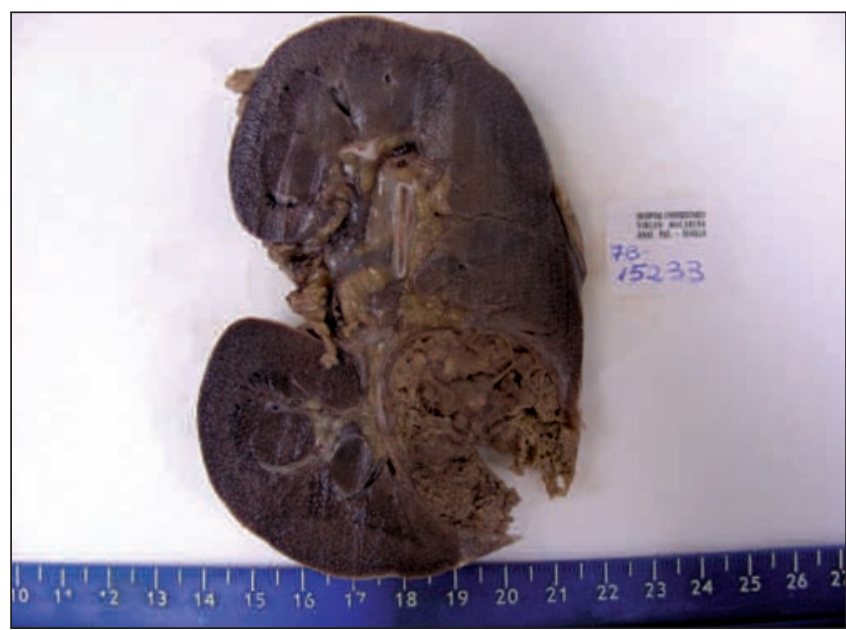

Fig. 2. 
El carcinoma de células renales de tipo papilar tiene un patrón característico de anormalidades genéticas basado en ganancias cromosómicas. Lo más común es la trisomía o tetrasomía de 7 y 17. A este paciente se le determinó si existía alguna anormalidad genética pero no se encontró.

El carcinoma de células renales puede presentar abundantes síntomas paraneoplásicos; se encuentran presentes en el 40\% de carcinoma de células renales durante el curso de la enfermedad. La importancia de estos síntomas es que pueden ser los precursores del comienzo de la enfermedad o de su recurrencia.

La presencia de manifestaciones paraneoplásicas no necesariamente implica un mal pronóstico o enfermedad metastásica (2).

Es el síndrome constitucional la manifestación paraneoplásica de un tercio de los pacientes: fiebre, pérdida de peso y náuseas. Los síntomas que forman parte del cuadro constitucional del carcinoma de células renales están mediados por citoquinas.

Otras citoquinas como IL-1, interferones y prostaglandinas han sido relacionados como posibles agentes del cuadro constitucional asociado al carcinoma de células renales (3).

Por ello, según diversos estudios, la sobreproducción de prostaglandinas por el tumor puede contribuir a la patogénesis de algunas de las manifestaciones paraneoplásicas incluyendo la diarrea, el rubor, la fiebre, etc. (4).

\section{BIBLIOGRAFÍA}

1. Delahunt B, Eble JN. Papillary renal cell carcinoma: a clinicopathologic and immunohistochemical study of 105 tumors. Modern Pathology 1997; 10 : 537-44.

2. Palapattu GS, Kristo B, Rajfer J. Paraneoplastic syndromes in urologic malignancy: the many faces of renal cell carcinoma. Rev Urol 2002; 4 (4): $163-70$.

3. Robertson RP, Bay link DJ, Metz SA. Plasma prostaglandin E in patients with cancer with and without hypercalcemia. J Clin Endocrinol Metab 1976; 43: $1330-5$.

4. Metz SA, McRae JR, Robertson RP. Prostaglandins as mediators of paraneoplastic syndromes. Metabolism 1981; 30: 299-316. 